Калинина В.Д.

\title{
Самостоятельная работа над развитием понимания об устойчивом развитии на занятиях по английскому языку в вузе
}

Российская академия народного хозяйства и государственной службы при Президенте Российской Федеращии (Россия, Москва)

doi: 10.18411/lj-02-2021-135

idsp: ljournal-02-2021-135

\section{Аннотация}

Данная статья обсуждает самостоятельную работу студентов с общедоступными онлайн ресурсами для достижения целей развития понимания об устойчивом развитии у студентов нелингвистического вуза, в результате которой достигается троякая цель: выстраивается система идей, связанных с пониманием необходимости устойчивого развития (sustainable development), рост лингвистических и обще-профессиональных компетенций.

Ключевые слова: устойчивое развитие, массовые открытые онлайн курсы (МООК), дискурс, самостоятельная работа, самоконтроль и самооценка, компетентность.

\section{Abstract}

This article focuses on independent work of students at business school who work with free online resources in order to broaden their understanding of what "sustainability" means. The benefit of this independent work of students is triple bottom line: building up systematised knowledge about sustainability and sustainable development, growth of linguistic and general professional competences.

Key words: sustainability, sustainable development, MOOC, discourse, independent work, self-control, self-assessment, competence.

Профессиональное обучение находится в тесной зависимости и связи с практическими требованиями современного мира. Забота о способности современных и будущих поколений устойчиво развиваться и осуществлять гармоничную хозяйственную деятельность являлось и всегда будет являться насущной необходимостью для всех. Обеспокоенность тем, что устойчивое и гармоничное развитие человечества останется несбыточной мечтой растет с каждым днем в ситуации общей нестабильности. Тем более важной становится работа по разъяснению и воспитанию понимания что есть устойчивое развитие и как оно может быть достигнуто в различных странах и регионах.

Студенты института бизнеса и делового администрирования Российской академии народного хозяйства и государственной службы при Президенте РФ (РАНХиГС) проходят подготовку по направлению «Международный менеджмент». Данная квалификация подразумевает осуществление успешной экономической деятельности и коммуникации на одном или нескольких иностранных языках в межкультурном пространстве. Поэтому формирование у будущих лидеров бизнеса осознания важности устойчивого развития является приоритетным в нашей школе бизнеса, как и хорошее знание иностранных языков. Преподавание иностранных языков в числе других дисциплин способствует формированию жизненно важных общекультурных, обще-профессиональных и профессиональных компетенций бакалавров по направлению подготовки «Международный менеджмент», в том числе, развитию критического и творческого мышления.

Цель настоящей статьи заключается в том, чтобы показать возможности использования заданий для самостоятельной работы с онлайн ресурсами по 
определенной тематике (sustainable development) для развития критического осмысления понятия «устойчивое развитие» и творческого подхода к применению принципов устойчивого развития на практике.

Массовые открытые онлайн курсы (МООК) используют работу преподавателей лучших университетов и целый диапазон каналов обратной связи между курсантами и преподавателями, они широко доступы и бесплатны. При таких преимуществах неудивительно, что в последнее время многие вузовские преподаватели стали прибегать к использованию онлайн программ, курсов и ресурсов для дополнения работы оффлайн.

Наши преподаватели отмечают, что широкая популяризация привела к размыванию и упрощению смысла «устойчивого развития», большинство первокурсников рассматривают понятие «sustainability" как синоним «еco-friendliness", или просто долговременное экономическое развитие. Однако, исследование современного дискурса, в особенности дискурса Организации Объединенных Наций, показывает, что понятие «устойчивое развитие» теперь включает в себя и понятие долгосрочного реального экономического роста, и бережное, бережливое использование природных ресурсов, и честную политику по отношению к человеческим ресурсам.

Многочисленные образовательные онлайн платформы на английском языке предлагают интересные курсы для развития идей и понятий устойчивого развития. Futurelearn является одной из тех платформ, которые щедро делятся своими ресурсами, где собрано большое количество курсов, в частности Organising for the Sustainable Development Goals (SDGs) Hanken School of Economics и Concepts in Sustainable Development University of Leicester. Оба упомянутых курса систематизируют представления обучаемых об устойчивом развитии, расширяют кругозор, углубляют понимание. При последовательном изучении материалов курсов обучающиеся актуализируют знания о том, что такое Цели устойчивого развития (Sustainable Development Goals - SDGs), сформированные и сформулированные ООН как часть глобальной повестки Устойчивого развития 2030, принятой 193 странами, членами ООН. Оба курса расширяют понимание sustainability до включения в него 17 основных направлений устойчивого развития:

- Ликвидация нищеты - No poverty,

- Ликвидация голода - Zero hunger,

- Хорошее здоровье и благополучие - Good health and well-being,

- Качественное образование - Quality education,

- Гендерное равенство - Gender equality,

- Чистая вода и санитария - Clean water and sanitation,

- Недорогостоящая и чистая энергия - Affordable and clean energy,

- Достойная работа и экономический рост - Decent work and economic growth,

- Индустриализация, инновации и инфраструктура - Industry, innovation and infrastructure,

- Уменьшение неравенства - Reduced inequalities,

- Устойчивые города и населенные пункты - Sustainable cities and communities,

- Ответственное потребление и производство - Responsible consumption and production,

- Борьба с изменением климата - Climate action,

- Сохранение морских экосистем - Life below water,

- Сохранение экосистем суши - Life on land, 
- Мир, правосудие и эффективные институты - Peace, justice and strong institutions,

- Партнерство в интересах устойчивого развития - Partnerships for the goals.

Самостоятельная работа студентов неязыковых вузов по иностранному языку не является основополагающим видом работы. Тогда как учебная деятельность по профильным дисциплинам требует от обучаемых большого объёма самостоятельной работы с различными источниками, аудиторная система обучения иностранным языкам имеет ограниченные возможности для регулирования и мотивирования этого процесса. Наш эксперимент заключался в том, чтобы активизировать самостоятельную работу, ознакомить студентов с комплексом идей устойчивого развития и углубить их понимание об основных направлениях деятельности. Это позволило бы не только сформировать знание по данному предмету (I know), но и развивать целый комплекс компетенций (I can). Методом для достижения поставленной цели послужило самостоятельное выполнение студентами учебных заданий на платформе Futurelearn c последующей презентацией результатов изучения материала в форме краткого доклада, который впоследствии обсуждается в аудитории.

Самостоятельная работа (согласно положениям исследования И.А. Зимней) - это высшая форма учебной деятельности, форма самообразования, связанная с работой в аудитории. Самостоятельная работа студентов третьего курса, которые стали участниками данного эксперимента, имела все характеристики процесса самообразования, так как перед участниками стояли познавательные задачи, это была, в целом, самоорганизуемая и саморегулируемая деятельность, которая опиралась на самоконтроль и самооценку студентов. Выполнение заданий открытого общедоступного курса Школы экономики Ханкен, который мы выбрали для эксперимента, было модульным, динамичным и дополняющим по тематике к основному курсу английского языка для специальных целей.

Задание было выдано студентам в форме инструкции: Зарегистрируйтесь на платформе Futurelearn.com, чтобы пройти обучение по курсу Organising for the Sustainable Development Goals (SDGs) Hanken School of Economics. В конце каждой недели обучения будьте готовы предоставить краткий устный отчет по изученному на занятии. Будьте готовы отвечать на вопросы по докладу и к обсуждению положений пройденного.

В результате эксперимета систематическая самостоятельная работа над заданиями курса Organising for the Sustainable Development Goals (SDGs) Hanken School of Economics помогала студентам достигать троякой цели: изучение специфического предмета, развитие лингвистических компетенций и развитие обще-профессиональных и обще-культурных компетенций, в частности, критического мышления.

Во время презентации доклада воспринимающая аудитория работала над заданием прослушать и задать вопрос докладчику для уточнения или дальнейшего развития темы. Дискуссия являлась завершающим этапом работы над самостоятельной работой. В результате этой работы обучаемые отмечали сами, и демонстрировали, расширение тематического словаря, развитие специфического понятийного аппарата, критическое осмысление идей и возможность к их творческому развитию. Таким образом, следствием данного эксперимента стала активизация самостоятельной работы обучаемых, вовлечение группы в рецептивную и продуктивную речевую деятельность и росту целого комплекса компетентностей .

$$
* * *
$$

1. Зимняя И.А. Педагогическая психология. Учебник для вузов. Изд. второе, доп., испр. и перераб. М.: Издательская корпорация «Логос», 1999. - 384 с. 
2. Конышева А.В. Организация самостоятельной работы учащихся по иностранному языку. - Спб.: КАРО, Мн.: Издательство «Четыре четверти», 2005. - 208 с.

3. Соловова Е.Н. Методика обучения иностранным языкам: продвинутый курс: пособие для студентов пед. вузов и учителей/ Е.Н. Соловова. - М.: АСТ: Астрель, 2008. - 272 с.

4. Полат, Е.С. Современные педагогические и информационные технологии в системе образования [Текст]: учеб. пособие для студентов высш. учеб. заведений / Е.С. Полат, М.Ю. Бухаркина. - М.: Издательский центр «Академия», 2007. - 368 с.

5. Щукин, А.Н. Современные интенсивные методы и технологии обучения иностранным языкам [Текст]: учебное пособие / А.Н. Щукин. -М.: Филоматис, 2008. - 180 с.

6. Халперн Д. Психология критического мышления. - СПб. : Питер, 2000. - 512 с.

7. https://www.un.org/sustainabledevelopment/ru/sustainable-development-goals.

8. https://www.futurelearn.com/courses/sustainability.

9. https://www.futurelearn.com/courses/organising-for-sustainable-development-goals.

\section{Кирюшина О.В. \\ Специфика преподавания иностранного языка в контексте дистанционного образования}

Нижнетагильский государственный соџиально-педагогический институт, филиал РГППУ

(Россия, Нижний Тагил)

doi: $10.18411 / l j-02-2021-136$

idsp: ljournal-02-2021-136

\section{Аннотация}

В статье рассматриваются преимущества и недостатки дистанционного формата обучения, проблемы и трудности его реализации, а также особенности обучения иностранному языку в удаленном режиме. Анализируется опыт работы по реализации дистанционного обучения у студентов высшего учебного заведения и даются рекомендации по итогам проведенной работы.

Ключевые слова: дистанционное образование, дистанционный формат обучения, модель преподавания иностранного языка, обучение аспектам иностранного языка, обучение видам речевой деятельности.

\section{Abstract}

The article discusses the advantages and disadvantages of the distance learning format, the problems and difficulties of its implementation, as well as the features of teaching a foreign language remotely. The experience of work on the implementation of distance learning among students of a higher educational institution is analyzed and recommendations are given based on the results of the work done.

Keywords: distance education, distance learning format, foreign language teaching model, teaching aspects of foreign language, teaching the types of speech activity.

В большинстве высших учебных заведений в последние годы преподавателей активно призывали разрабатывать дистанционные курсы, наполнять разные электронные оболочки, создавать электронную образовательную среду. Для этого организовывали курсы повышения квалификации по дистанционному образованию. Большинство преподавателей откликались, однако делалось это зачастую достаточно формально, потому что прежде всего не было понимания, зачем это нужно. Однако в связи с появлением коронавируса и ухудшением эпидемиологической обстановки в нашей стране и во всем мире потребовался резкий и неожиданный переход всей образовательной системы в дистанционный формат. Теперь уже ни у кого не осталось сомнений, что дистанционный формат обучения нужен. Да, он не может и не должен полностью заменить очный, но при качественной организации может стать важным дополнением к очному обучению и заменой очного формата в критической ситуации. 